\title{
Actuación parlamentaria y diferencias de género en Uruguay ${ }^{1}$
}

Niki JOHNSON

\section{Introducción}

$\mathrm{E}$

n América Latina el tema del acceso de las mujeres a espacios y cargos políticos formales cobró importancia en la agenda feminista y visibilidad en la agenda pública durante el proceso de redemocratización, cuando las mujeres políticas y las mujeres organizadas de la sociedad civil advertían que "Si la mujer no está, la democracia no va". Ante la renuencia generalizada de los partidos políticos a ceder lugar y menos a promover activamente a aquellas militantes que buscaban desarrollar su carrera política en los más altos niveles, en los 90 la lucha de las mujeres por efectivizar su derecho político formal a ser elegidas y revertir su tradicional exclusión de este bastión de dominio masculino en América Latina, se centró en la demanda por la aplicación de cuotas por sexo en las listas electorales, como un mecanismo transitorio para asegurar y acelerar el acceso de las mujeres a cargos electivos ${ }^{2}$.

En el debate sobre la cuota, sus partidarias/os manejaban una serie de argumentos "consecuencialistas" (Htun y Jones, 2002: 35) referidos a los potenciales impactos de la incorporación de más mujeres a cargos de toma de decisiones. Estas argumentaciones parten de la suposición de que mujeres y hombres tienen formas distintas de hacer política, ya sea como resultado de diferencias "naturales" o de la diferente socialización

1. Este artículo se basa en parte en el proyecto de investigación "Género y legislación en el Uruguay, 1985-2003", llevado a cabo en 2001-2004 por la autora, financiado por la Comisión Sectorial de Investigación Científica de la Universidad de la República, Uruguay.

2. Se aprobaron leyes de cuotas en Argentina en 1991, en México y Paraguay en 1996, en Bolivia, Brasil, Costa Rica, Panamá, República Dominicana, Venezuela, Ecuador y Perú en 1997, y en Colombia (para cargos designados del Poder Ejecutivo) y de nuevo en Ecuador y Perú en 2000 (ver Peschard, 2004 y Htun y Jones, 2002). 
de género que reciben. Por lo tanto, se razona, es necesario que la visión específicamente femenina de las mujeres se integre a la política: o para no perder un rico recurso social; o para lograr la inclusión de temas previamente excluidos o marginados en la agenda política y que atañen particularmente a las mujeres; o para garantizar la promoción y defensa de los intereses específicos de género de las mismas.

Este razonamiento plantea entonces el reto para la ciencia política feminista de demostrar empíricamente si realmente existen o no diferencias entre la forma de hacer política de mujeres y hombres en los ámbitos de la política institucional. En América Latina, los estudios sobre la participación de las mujeres en cargos políticos formales electivos han tendido a centrarse en los obstáculos al ingreso de las mujeres, y en el impacto y efectividad de la cuota como mecanismo para superar esas barreras, más que en la actuación de las mujeres una vez que lleguen a ocupar un cargo $^{3}$. En cambio, en otras regiones del mundo y, especialmente, en la década de los 90, empezaron a aparecer estudios sobre las diferencias de género en la actuación parlamentaria y la producción legislativa, y sobre la cuestión de si tener a mujeres en cargos electivos aseguraba una mejor representación de los intereses de las mismas. Estos estudios muestran que en el ámbito parlamentario las diferencias de género pueden expresarse de múltiples maneras, por ejemplo, en los temas introducidos en la agenda legislativa, en los valores transmitidos y promovidos a través de las iniciativas legislativas, en los estilos de liderazgo o de relacionamiento con colegas, en el uso del lenguaje y el estilo retórico. Pero no siempre el género aparece como un clivaje significativo en la actuación parlamentaria, y algunas investigaciones señalan que hay mayores similitudes que diferencias entre hombres y mujeres políticos. No obstante, algunos estudios sobre los Estados Unidos han mostrado que, comparadas con sus pares hombres, las mujeres en el Congreso y en los órganos legislativos subnacionales defienden más los derechos de las mujeres y son más proclives a presentar proyectos en áreas relacionadas con el rol tradicional femenino o a adoptar posiciones y comportamientos compatibles con el feminismo (ver Thomas, 1994; Dodson y Carroll, 1991; Swers, 1998). Investigaciones sobre los países escandinavos encontraron que existía una división de la actividad parlamentaria basada en el género, en cuanto al tipo y contenido de iniciativas legislativas, y que eran las mujeres las que promovían los temas de género o de mujeres en la agenda parlamentaria (Sinkkonen y Haavio-Mannila, 1981; Skard y Haavio-Mannila, 1985). Finalmente, algunos estudios sobre Canadá concluyen que la "conciencia feminista" es una variable más significativa que el sexo, mientras que el partido político también tiene relevancia para explicar las diferencias en las actitudes y acciones (Tremblay, 1998; Tremblay y Pelletier, 2000; Trimble, 1997 y 1998).

3. Una notable excepción es De Barbieri (2003). También ver Fernández Poncela (2004). 
El presente artículo pretende testear para el caso uruguayo la hipótesis de que las mujeres hacen un aporte específico qua mujeres a la agenda y a los procesos legislativos, tomando como universo de análisis el Parlamento uruguayo y centrándose en dos preguntas principales: (1) ¿Se pueden identificar diferencias de género en la actuación parlamentaria de hombres y mujeres legisladores? Y (2) ¿Las mujeres legisladoras representan a las mujeres en su quehacer legislativo? Abarcar todas las posibles dimensiones de la actuación política de hombres y mujeres parlamentarios supera el alcance del presente estudio, el cual se centra principalmente en la dimensión temática de la agenda parlamentaria. Las preguntas específicas que se tomaron para orientar el análisis son cuatro: ¿Se reproduce en el trabajo legislativo la tradicional división sexual del trabajo que relaciona a las mujeres con la esfera y los temas reproductivos y a los hombres con la esfera y temas productivos? ¿La labor parlamentaria de las mujeres se orienta según una "ética del cuidado" (Gilligan, 1982), caracterizada por un juicio más contextual, basado en la comprensión del mundo como una red de relaciones y en la responsabilidad por los demás, en particular por los más indefensos? ¿Las legisladoras promueven los temas de género y defienden los derechos de las mujeres en la agenda parlamentaria? En caso de una respuesta positiva, ¿qué estrategias adoptan para promover esa agenda legislativa de género?

Cualquier estudio sobre las diferencias de género en la actuación parlamentaria de mujeres y hombres ha de tomar en cuenta, además, la dimensión cuantitativa de la presencia femenina. Drude Dahlerup (1993) argumenta que mientras las mujeres siguen siendo una minoría pequeña en ámbitos tradicionalmente dominados por varones, es difícil que resistan la presión de "masculinizarse", es decir, de adoptar las prácticas y formas masculinas de hacer política; en cambio, las que sí se animan a plantear su diferencia y trabajar desde su condición específica de mujeres políticas, generalmente se sienten muy aisladas y expuestas. Como señala Kathleen Jones (1993: 103), en un contexto donde el liderazgo sigue siendo "fuertemente codificado, en términos culturales, con signos de masculinidad", las emergentes líderes mujeres se enfrentan al dilema de "o llamar la atención a lo femenino y correr el riesgo de perder autoridad, o adoptar normas masculinas y arriesgarse a la desaprobación social". El ingreso de más mujeres a tales ámbitos, por lo tanto, se vuelve una condición necesaria para transformar estos patrones de adaptación y el significado mismo del liderazgo político, pero no una condición suficiente. Según Dahlerup (1993: 176-177), para que una minoría llegue a ser una "masa crítica", es necesario, además de la dimensión numérica, "un cambio cualitativo en las relaciones de poder" que llevan a "situaciones en las cuales el tamaño incrementado de la minoría hace posible que el grupo minoritario empiece a cambiar la estructura de poder, y por lo tanto, su propio estatus como minoría". 
Uruguay tiene una de las tasas más bajas de representación femenina parlamentaria en la región ${ }^{4}$. En las primeras elecciones posdictadura, ninguna mujer fue electa como titular al Parlamento uruguayo. A partir de entonces, la tasa de representación femenina parlamentaria aumentó paulatinamente de elección en elección hasta las últimas elecciones de 2004, cuando se registró un leve retroceso (ver Cuadro 1).

\section{Cuadro 1}

Evolución de la representación femenina parlamentaria en Uruguay, 1984-2004

\begin{tabular}{lccc}
\hline Elecciones año & \multicolumn{3}{c}{ Porcentaje de mujeres electas como titulares } \\
\cline { 2 - 4 } & Parlamento & Senado & Cámara de Representantes \\
\hline $\mathbf{1 9 8 4}$ & 0,0 & 0,0 & 0,0 \\
$\mathbf{1 9 8 9}$ & 4,6 & 0,0 & 6,1 \\
$\mathbf{1 9 9 4}$ & 6,9 & 6,5 & 7,1 \\
$\mathbf{1 9 9 9}$ & 11,5 & 9,7 & 12,1 \\
$\mathbf{2 0 0 4}$ & 10,8 & 9,7 & 11,1 \\
\hline
\end{tabular}

Fuente: Elaboración propia en base a datos de la Corte Electoral.

Para el presente análisis se eligió estudiar la XLV legislatura (2000-2005), por dos razones. Primero, en la perspectiva histórica, las elecciones parlamentarias de 1999 marcaron un avance importante en el ingreso de mujeres al Parlamento, con tres mujeres electas como senadoras titulares (del total de 31 senadores) y doce electas como diputadas titulares (del total de 99 diputados). Y segundo, las mujeres electas empezaron a mostrar algunas características de una "masa crítica", concretamente en tanto formaron coaliciones para promover en la agenda legislativa una serie de temas previamente marginados y directamente relacionados con los intereses del grupo social al que pertenecen ${ }^{5}$. Cabe señalar, de todas

4. La actual tasa de representación femenina en la Cámara de Representantes de un 11,1 por ciento ubica a Uruguay en la posición 92 de la Clasificación Mundial de Mujeres en los Parlamentos de la Unión Interparlamentaria, muy por debajo del promedio regional para las Américas (19,6 por ciento), y en el lugar 15 del ranking de 19 países latinoamericanos. Ver http://www.ipu.org/wmn-e/classif.htm

5. Esto contrasta con la sensación de aislamiento y exposición, propia de una pequeña minoría, expresada por legisladoras uruguayas titulares en el período anterior (1990-1995) en entrevistas realizadas en 1996-7 en el marco de otra investigación: "Cuando hablábamos las mujeres en la Cámara, era como un silencio, o sea, a ver qué decíamos, a ver si éramos capaces, a ver qué pasaba con nosotras. [...] Era como un examen permanente, una exigencia o una expectativa de sobrerrendimiento" / "En un ambiente puro de hombres como es [el Parlamento] hay hasta lenguaje diferente, las costumbres, [...] las cosas que se consideran normales. Entonces, como que las mujeres supuestamente tendrían que adquirir hábitos -o sea parecerse al hombre- para poder estar aquí adentro". Citado en Johnson (2000), p. 80. 
formas, que el número reducido de casos (15 legisladoras en total) no permite proyectar conclusiones generalizables acerca de las diferencias de género en la actuación parlamentaria de hombres y mujeres.

Este estudio se limita por lo tanto a explorar las posibles diferencias de género en la actuación parlamentaria de un elenco parlamentario específico, y en sólo algunas de sus múltiples dimensiones.

\section{Diferencias de género en la actuación parlamentaria}

En esta primera sección se pretende evaluar si existen o no diferencias de género en la actuación parlamentaria de legisladoras y legisladores titulares del parlamento uruguayo en la XLV legislatura6. Para esto se coteja la actuación de todas las legisladoras titulares ( 3 senadoras y 12 diputadas) con la de una muestra de 15 legisladores varones, todas/os electas/os por uno de los tres principales partidos con representación parlamentaria -la coalición de izquierda Encuentro Progresista-Frente Amplio (EP-FA), y los dos partidos fundacionales, el Partido Colorado (PC) y el Partido Nacional $(\mathrm{PN})^{7}$. Se eligió trabajar con una muestra intencional, ponderada por cargo, partido político, reelección y departamento (Montevideo-interior), para controlar así la incidencia de otras variables potencialmente explicativas de las diferencias en la actuación de los y las parlamentarios / as.

Las actividades parlamentarias que se tomaron para hacer el análisis fueron: primero, la participación como miembros y delegados / as en comisiones (permanentes, especiales e investigadoras) ${ }^{8}$; y segundo, la presentación de exposiciones escritas (EE) y verbales (EV), pedidos de informes (PI) y proyectos de ley (PL) ${ }^{9}$. Se eligieron estos dos grupos de indicadores por reflejar los dos principales entornos de actuación parlamentaria.

6. La legislatura se extiende del 15 de febrero de 2000 al 14 de febrero de 2004 .

7. En el período bajo estudio, el PC y el PN formaban un gobierno de coalición, bajo un presidente colorado, y el EP-FA estaba en la oposición (como lo había sido desde que se fundó en 1971) junto con el Nuevo Espacio, un partido menor sin representación femenina en el parlamento.

8. Tanto en el Senado como en la Cámara de Representantes existen 16 comisiones permanentes y varias especiales, investigadoras o integradas (que pueden integrar miembros tanto de comisiones permanentes como de especiales) que abordan temáticas específicas o puntuales.

9. Este segundo grupo de indicadores de alguna manera abarca el triple rol que, según lo establecido en la Constitución y los Reglamentos de las respectivas Cámaras, compete a las y los integrantes del Poder Legislativo uruguayo: legislar (modificando o derogando leyes obsoletas y concretando nuevas normas legislativas conformes a los valores de la sociedad); representar (recibiendo y mediando los intereses e inquietudes de la ciudadanía); y fiscalizar (ejerciendo una función de contralor sobre las acciones de los otros poderes del estado, en particular el Poder Ejecutivo). 
Las diferencias de género entre la actuación de mujeres y hombres legisladores se miden en dos dimensiones. La primera se refiere al alcance de su actuación (número de comisiones en las que participan y cantidad de EE, EV, PI y PL presentados); la segunda tiene que ver con las temáticas en las cuales se centra su actuación parlamentaria. Con referencia a este segundo indicador, se optó por seguir la tipología usada por Skard y Haavio-Mannila (1985: 73), que clasifica las iniciativas legislativas en los parlamentos escandinavos en tres grandes grupos. Primero, las que tienen que ver con la reproducción (entendida como la actividad que asegura la devolución de la mano de obra, el capital y los recursos primarios a la producción y cuya esfera abarca el ámbito doméstico y aquellos ámbitos públicos que se encargan de tareas de cuidado, crianza y educación). Segundo, las relacionadas con la producción (es decir, la producción de bienes y servicios a cambio de un pago en el mercado laboral que tiene lugar dentro del mercado, en los hogares y en el sistema público). Y tercero, las relativas a lo que llaman la preservación del sistema (todo lo relacionado con el orden y la administración).

Para los propósitos del análisis, entonces, entran en la categoría reproducción las temáticas de la agenda parlamentaria relacionadas con las políticas sociales, la familia, salud, educación, vivienda, medio ambiente, educación, cultura y las políticas hacia los consumidores. La categoría producción abarca temáticas laborales, fiscales y económicas, y temas vinculados a la industria y la energía, la producción primaria, las obras, las comunicaciones y el transporte y las políticas de desarrollo regional. Y finalmente, la categoría preservación del sistema incluye temáticas relacionadas con el mantenimiento y la reforma de los sistemas burocrático y político, la política exterior y la defensa nacional, el derecho penal, y el apoyo a los grupos de interés y las minorías.

Un estudio sobre el impacto de las mujeres en la agenda legislativa en el caso de Finlandia muestra que para el período 1907-1977 existía una clara división del trabajo entre parlamentarios hombres y mujeres: aquéllos se concentraban mayoritariamente en los temas productivos, mientras que éstas atendían más a temas reproductivos; también existía una mayor tendencia masculina a tratar temas relativos a la preservación del sistema (citado en Skard y Haavio-Mannila, 1985: 73-74). Otro estudio sobre los proyectos de ley presentados al Parlamento sueco en la década de los setenta también reveló que las iniciativas presentadas por las mujeres se concentraban en las problemáticas de la educación y las políticas sociales y que raramente tocaban temas económicos; en cambio, las propuestas impulsadas por los hombres en su mayoría trataban asuntos fiscales y temáticas relacionadas con el comercio y la industria. Además, los datos mostraban que el desequilibrio en lo que llaman el "perfil temático" era más marcado en el caso de las mujeres que para los hombres (citado en Skard y Haavio-Mannila, 1985: 74). 


\section{Participación en comisiones parlamentarias}

El primer indicador que tomamos para el análisis es la participación en las comisiones parlamentarias. Al examinar la composición y distribución de las comisiones se nota que, trasladada al ámbito político, la división entre reproducción y producción se traduce en una jerarquización valorativa de ésta sobre aquélla. La mayor jerarquía de las comisiones productivas se refleja tanto en la mayor cantidad de comisiones permanentes en esta categoría (14, contra 9 reproductivas) como en su número de integrantes: las reproductivas tienen un promedio de 6 integrantes, y sólo una tiene 9 miembros; en cambio, de las productivas cinco tienen 9 miembros y entre todas tienen un promedio de 7 integrantes. Sigue existiendo, entonces, la percepción de que los "grandes temas" (o temas "duros") de la política son los que tienen que ver con la economía, los asuntos internacionales y la defensa nacional, mientras que los temas políticos "menores" (o "blandos") se relacionan con la cotidianeidad y el ámbito doméstico.

El reglamento respectivo de cada Cámara establece las reglas según las cuales se determina la integración de las comisiones ${ }^{10}$. En el caso de la Cámara de Representantes, cada diputada/o (menos el o la presidente / a de la Cámara) debe integrar una (y sólo una) comisión permanente como miembro pleno (es decir, con voz y voto); en el Senado, dado que hay menos legisladores pero la misma cantidad de comisiones, cada senador/a puede integrar más de una comisión como miembro pleno. Además, en ambas Cámaras, todo sector político (es decir, fracción partidaria) que no esté representado en una comisión tiene derecho a hacerse oír en ella por intermedio de un/a delegado/a, que tiene voz sin voto. Al principio de cada legislatura se define el número de integrantes para cada comisión y la distribución relativa de cargos entre los sectores políticos (que corresponde a la correlación de fuerzas en la Cámara) ${ }^{11}$. La designación de los y las miembros de las comisiones depende de la negociación interna y la correlación de fuerzas al interior de cada bancada partidaria. Además, en todos los partidos se toman en cuenta en lo posible la formación, experiencia y preferencias personales de cada legislador $/ \mathrm{a}^{12}$.

El Cuadro 2 muestra que globalmente las mujeres participan en más comisiones que los hombres. Aquéllas participan en un promedio de 4 comisiones, mientras que éstos participan en un promedio de 3.

10. Ver Reglamento de la Cámara de Senadores, artículos 141-146; Reglamento de la Cámara de Representantes, artículos 15-18, 132.

11. En el actual período, en el Senado las comisiones permanentes se componen de 5 a 9 miembros y en la Cámara de Representantes de entre 3 y 9.

12. El análisis cuantitativo no puede captar la sutil combinación de factores que inciden en la designación de cada integrante de cada comisión. Pero en las entrevistas realizadas a las legisladoras en el marco del proyecto se estableció que las designaciones reflejan por lo menos un punto mínimo de coincidencia entre el interés del legislador/a y la necesidad del sector. 
Cuadro 2

Participación en comisiones por sexo

\begin{tabular}{llccc}
\hline \multirow{2}{*}{ Total } & & Mujeres & Hombres & Total \\
Comisiones reproducción & Número & 28 & 12 & $\mathbf{1 0 4}$ \\
\hline \multirow{2}{*}{ Comisiones producción } & Número & 46,7 & 27,3 & 40 \\
& \% del total & 20 & 21 & 38,5 \\
Comisiones sistema & Número & 12 & 47,7 & 41 \\
& \% del total & 20,0 & 11 & 39,4 \\
& & 25,0 & 23 \\
\hline
\end{tabular}

Fuente: Elaboración propia en base a datos del sitio web del Parlamento uruguayo (www.parlamento.gub.uy).

Si comparamos la distribución de la participación entre hombres y mujeres según la temática de las comisiones, vemos que la mayor tasa total de participación femenina responde en gran medida a su mayor presencia en las comisiones reproductivas. No obstante dicha circunstancia, también puede advertirse que la presencia de las mujeres en las otras dos categorías de comisiones es similar a la de los hombres. Esto último evidencia que la reproducción de la tradicional división sexual del trabajo en el Parlamento uruguayo es tal hasta cierto punto: aunque las legisladoras se sienten más convocadas que sus pares varones para integrar las comisiones vinculadas a la esfera de la reproducción, también tienen una presencia importante en las comisiones productivas, donde la diferencia entre mujeres y hombres es mínima (21 instancias de participación a 20).

Si ahora cruzamos la variable sexo con la de partido político, se nota (Cuadro 3) que la tendencia a una mayor participación en comisiones entre las mujeres se mantiene en todos los partidos, siendo especialmente fuerte la brecha de género interna partidaria en el caso del PC, donde la tasa de participación masculina equivale a sólo un 56,5 por ciento de la tasa de participación femenina.

No obstante, la tasa de participación de las coloradas no supera la de los varones de los otros dos partidos, como sí lo hace la tasa respectiva de las frenteamplistas y blancas. Esta última diferencia intra-sexo refleja la incidencia de la variable "partido", en particular referido a su estatus oficialista u opositor, y al grado de fraccionalización interna de su bancada parlamentaria. El tamaño absoluto de la bancada frenteamplista (52) supera la colorada (44), por lo que se podría esperar que tuviera una tasa de participación promedio por legislador menor a ésta. Sin embargo, en esta legislatura el EP-FA está en la oposición ${ }^{13}$, y por lo tanto el Parlamento es

13. Aunque el EP-FA recibió más votos que el PC en la primera vuelta (que define las elecciones parlamentarias), no alcanzó la mayoría absoluta necesaria para ganar la presidencia, la cual fue definida en el balotaje posterior, que ganó el PC. 
el único ámbito desde el cual tiene posibilidad de incidir directamente en la política nacional, y desde donde puede fiscalizar las acciones del Poder Ejecutivo. Además, es el partido con el más alto grado de fraccionalización, lo que implica que muchos sectores frenteamplistas no tienen una participación directa (miembros plenos) en las comisiones permanentes. Son estos factores, entonces, que hacen que el EP-FA tenga una participación adicional (delegados) mayor en las comisiones.

\section{Cuadro 3}

Participación en comisiones por sexo y partido

\begin{tabular}{llcc}
\hline Partido & Sexo & Número de comisiones en las que participan & Tasa de participación \\
\hline \multirow{2}{*}{ EP-FA } & Total & 67 & - \\
& Mujeres & 37 & 4,6 \\
& Hombres & 30 & 3,8 \\
PN & Total & 23 & - \\
& Mujeres & 14 & 4,7 \\
& Hombres & 9 & 3,0 \\
PC & Total & 14 & - \\
& Mujeres & 9 & 2,3 \\
& Hombres & 5 & 1,3 \\
\hline
\end{tabular}

Fuente: Elaboración propia en base a datos del sitio web del Parlamento uruguayo.

En cambio, aparte de que el PC es el partido de gobierno, sus 44 bancas se distribuyen internamente entre tan sólo dos fracciones, las cuales tienen por lo tanto casi garantizada una representación directa en todas las comisiones, sin necesidad de asistir en calidad de delegados. Estos dos hechos hacen que el PC tenga menos motivos por una participación adicional en las comisiones. Podemos concluir, entonces, que es la interacción entre las variables sexo y partido la que hace que las legisladoras coloradas tengan una mayor actuación que sus correligionarios varones, pero menor a la de los legisladores de los otros dos partidos.

Al desagregar la participación por partido y sexo según la temática de las comisiones (Cuadro 4) se ve que en los tres partidos las comisiones de reproducción concentran la mayor parte de la participación femenina (entre un $45 \%$ y un 50\%), y que, en general, son las comisiones sistémicas las que convocan menos participación, excepto en el caso de las coloradas.

Por su parte, los hombres participan más en las comisiones de producción -que para los legisladores del EP-FA representan la mitad de sus instancias de participación-, excepto en el caso de los colorados, que participan equitativamente en comisiones reproductivas y productivas. Cabe preguntarse si esta diferencia entre la participación de frenteamplistas y colorados se debe al distinto tamaño relativo de sus respectivas 
bancadas femeninas: las 8 legisladoras frenteamplistas representan un 15 por ciento de la totalidad de la bancada de su partido, mientras que las 4 coloradas representan sólo un 9 por ciento de la bancada colorada total. Es decir, al no haber tantas mujeres coloradas, los hombres necesariamente tienen que integrar las comisiones reproductivas, mientras que al haber más mujeres frenteamplistas se impone la lógica tradicional de la división de trabajo por sexo, aunque ésta es mucho menos marcada en el perfil temático de las legisladoras de este partido.

\section{Cuadro 4}

Participación en comisiones por partido y sexo, según temática

\begin{tabular}{|c|c|c|c|c|c|c|c|}
\hline & \multicolumn{2}{|c|}{ EP-FA } & \multicolumn{2}{|c|}{ PN } & \multicolumn{2}{|c|}{ PC } \\
\hline & & Mujeres & Hombres & Mujeres & Hombres & Mujeres & Hombres \\
\hline \multicolumn{2}{|c|}{ Total comisiones } & 37 & 30 & 14 & 9 & 9 & 5 \\
\hline \multirow{3}{*}{$\begin{array}{l}\text { Comisiones } \\
\text { reproducción }\end{array}$} & Número & 17 & 8 & 7 & 2 & 4 & 2 \\
\hline & $\begin{array}{l}\% \text { de su } \\
\text { participa- }\end{array}$ & & & & & & \\
\hline & ción total & 45,9 & 26,7 & 50,0 & 22,2 & 44,4 & 40,0 \\
\hline \multirow{3}{*}{$\begin{array}{l}\text { Comisiones } \\
\text { producción }\end{array}$} & Número & 13 & 15 & 5 & 4 & 2 & 2 \\
\hline & $\%$ de su & & & & & & \\
\hline & ción total & 35,1 & 50,0 & 35,7 & 44,4 & 22,2 & 40,0 \\
\hline \multirow{3}{*}{$\begin{array}{l}\text { Comisiones } \\
\text { sistema }\end{array}$} & Número & 7 & 7 & 2 & 3 & 3 & 1 \\
\hline & $\begin{array}{l}\% \text { de su } \\
\text { participa- }\end{array}$ & & & & & & \\
\hline & ción total & 18,9 & 23,3 & 14,3 & 33,3 & 33,3 & 20,0 \\
\hline
\end{tabular}

Fuente: Elaboración propia en base a datos del sitio web del Parlamento uruguayo.

Otro clivaje potencialmente significativo puede ser la distinción entre los/las diputados/as electos/as por Montevideo y los/las electos/as por departamentos del interior del país (ver el Cuadro 5) ${ }^{14}$.

Como es de esperar, los/las parlamentarios/as del interior, que pasan una parte de la semana en su departamento y por lo tanto tienen menos disponibilidad de tiempo para asistir a reuniones de las comisiones, tienen una tasa promedio de participación (1,5 comisiones por legislador / a) mucho menor que la de los/las representantes de Montevideo $(3,9)$. Con respecto a las diferencias por sexo, en el caso del interior, la partici-

14. Los/las senadores/as, se eligen en una única circunscripción nacional, por lo tanto no se incluyen en esta parte del análisis. También en este caso el total número de diputadas/os es 22 en vez de 24 . Esto se debe a que, a falta de una correspondencia directa para la muestra en el caso de una diputada del PN electa por Montevideo, se optó por incluir un diputado de Canelones, considerándose este departamento el más parecido al de la capital en términos de concentración poblacional, y otros indicadores socioeconómicos. Aquí no incluimos a estos dos casos para no sesgar los resultados. 
pación global en comisiones es paritaria entre hombres y mujeres, y el número de casos es tan reducido que es imposible determinar la relevancia de las diferencias por sexo en cuanto a la temática de las comisiones (las mujeres participan en dos comisiones sistémicas, mientras que los hombres no participan en ninguna, pero tienen una instancia más de participación en cada una de las otras categorías). En el caso de Montevideo, en cambio, las diputadas registran un 50 por ciento más de instancias de participación en comisiones que los diputados. La mayor parte de esa diferencia otra vez se debe a una alta tasa de participación femenina en comisiones reproductivas, aunque no a expensas de su participación en comisiones productivas, donde registran una participación casi a la par de la de los diputados. Éstos, en cambio, se concentran mayoritariamente en comisiones productivas, participando mucho menos en cualquiera de las otras dos categorías.

\section{Cuadro 5}

\section{Participación de diputados/as en comisiones por sexo y Montevideo/interior}

\begin{tabular}{lccccc}
\hline Departamento & Sexo & $\begin{array}{c}\text { Total } \\
\text { comisiones }\end{array}$ & $\begin{array}{c}\mathbf{N}^{0} \text { comisiones } \\
\text { reproducción }\end{array}$ & $\begin{array}{c}\mathbf{N}^{\circ} \text { comisiones } \\
\text { producción }\end{array}$ & $\begin{array}{c}\mathbf{N}^{0} \text { comisiones } \\
\text { sistema }\end{array}$ \\
\hline \multirow{2}{*}{ Interior } & Total & 12 & 5 & 5 & 2 \\
& Mujeres & 6 & 2 & 2 & 2 \\
\multirow{5}{*}{ Montevideo } & Hombres & 6 & 3 & 3 & 0 \\
& Total & 55 & 20 & 22 & 13 \\
& Mujeres & 33 & 15 & 10 & 8 \\
\multirow{2}{*}{ Total } & Hombres & 22 & 5 & 12 & 5 \\
\hline
\end{tabular}

Fuente: Elaboración propia en base a datos del sitio web del Parlamento uruguayo.

Finalmente en esta sección controlamos la incidencia de la variable reelección. Del total de 30 legisladoras/es, 12 fueron electas/os por primera vez en esta legislatura, mientras que el resto ya había ocupado una banca parlamentaria, ya sea como titular o suplente.

El Cuadro 6 muestra que los legisladores -tanto reelectos como nuevosparticipan más en comisiones productivas que en comisiones reproductivas o de sistema, siendo más marcado este desequilibrio en el perfil temático de los que asumen la banca por primera vez. A su vez, el perfil temático de las mujeres que ocupan el cargo por primera vez es la inversa, concentrándose su participación en comisiones reproductivas. El único grupo que rompe con la tradicional división de género son las mujeres reelectas, que participan más en comisiones de producción que en las de reproducción, aunque con una disparidad menor que en cualquiera de los otros casos. 


\section{Cuadro 6}

Participación en comisiones por reelección y sexo, según temática

\begin{tabular}{|c|c|c|c|c|c|}
\hline & \multicolumn{2}{|c|}{ Primera vez en el cargo } & \multicolumn{2}{|c|}{ Reelectas/os } \\
\hline & & Mujeres & Hombres & Mujeres & Hombres \\
\hline \multicolumn{2}{|c|}{ Total comisiones } & 30 & 20 & 30 & 24 \\
\hline \multirow[t]{2}{*}{$\begin{array}{l}\text { Comisiones } \\
\text { reproducción }\end{array}$} & Número & 17 & 5 & 11 & 7 \\
\hline & $\%$ de su participación total & 56,7 & 25,0 & 36,7 & 29,2 \\
\hline \multirow[t]{2}{*}{$\begin{array}{l}\text { Comisiones } \\
\text { producción }\end{array}$} & Número & 7 & 11 & 13 & 10 \\
\hline & $\%$ de su participación total & 23,3 & 55,5 & 43,3 & 41,7 \\
\hline \multirow[t]{2}{*}{$\begin{array}{l}\text { Comisiones } \\
\text { sistema }\end{array}$} & Número & 6 & 4 & 6 & 7 \\
\hline & $\%$ de su participación total & 20,0 & 20,0 & 20,0 & 29,2 \\
\hline
\end{tabular}

Fuente: Elaboración propia en base a datos del sitio web del Parlamento uruguayo.

Estos resultados nos sugieren dos hipótesis que las limitantes inherentes al enfoque analítico con el cual se eligió trabajar no permiten testear ${ }^{15}$. Una es que las mujeres cuando entran al ámbito parlamentario tienden a enfocar su labor en aquellas temáticas más relacionadas con su rol tradicional, pero en la medida en que se acostumbran al sistema y a las labores parlamentarias, van diversificando su enfoque temático para incluir especialmente más temas productivos. Otra es que las que ocupaban bancas en el período anterior, cuando el porcentaje de mujeres en el Parlamento era más bajo $(7,1 \%)$ y no existían las condiciones para generar una masa crítica femenina, se mimetizaron más con el modelo dominante masculino que jerarquiza los temas productivos. De todas formas, el desequilibrio productivo-reproductivo es mucho menos marcado en el perfil de las legisladoras reelectas que en el de sus pares varones.

\section{Actuación parlamentaria}

Pasemos ahora a examinar los cuatro actos parlamentarios -exposiciones escritas (EE), exposiciones verbales (EV), pedidos de informes (PI) y proyectos de ley (PL) - que integran el segundo indicador de actuación parlamentaria ${ }^{16}$. Vemos en este primer nivel de análisis (Cuadro 7) que otra

15. Para esto habría que comparar la participación en comisiones de mujeres reelectas en su primer período en el cargo con su participación en los períodos subsiguientes.

16. Cabe aclarar que se tomó como universo de estudio solamente aquéllos actos que eran de iniciativa exclusiva de cada legislador/a. Esto porque la naturaleza del sistema de registro parlamentario y las características particulares de la acción colectiva de las bancadas partidarias hacen que éstos sean los únicos actos a los que se puede adjudicar clara- 
vez las mujeres son más prolíficas que los hombres en todos los ítems bajo estudio.

\section{Cuadro 7}

Actos parlamentarios por sexo (número)

\begin{tabular}{lcccc}
\hline Sexo & Exposición verbal & Exposición escrita & Pedido de informes & Proyecto de ley \\
\hline Mujeres & 177 & 139 & 325 & 36 \\
Hombres & 175 & 28 & 146 & 27 \\
Total & 352 & 167 & 471 & 63 \\
\hline
\end{tabular}

Fuente: Elaboración propia en base a datos del sitio web y el Diario de Sesiones del Parlamento uruguayo.

Para analizar la incidencia de la variable sexo en la distribución según temática de los actos parlamentarios, tomamos como universo de análisis el conjunto de los EE, EV y PL presentados ${ }^{17}$. A las tres categorías temáticas utilizadas para el análisis de las comisiones -temas reproductivos, productivos y de sistema- se agrega aquí la categoría "otro" que abarca principalmente iniciativas que homenajean a personas, o conmemoran aniversarios de diversos tipos de acontecimientos, o proponen la denominación de rutas, escuelas, liceos u otras instituciones. El Cuadro 8 muestra que las mujeres presentaron más exposiciones y proyectos de ley que sus pares varones en todas las categorías, menos en el ítem "otro", siendo mayor la diferencia respecto a la categoría reproducción, donde sus iniciativas duplican las de los legisladores.

Si examinamos ahora la distribución por temática de los actos al interior de cada grupo -mujeres por un lado y hombres por otro- se nota que esta vez son las mujeres las que más fuertemente reproducen la tradicional división sexual del trabajo: los actos de legisladoras referidos a temas reproductivos representan un 42,8 por ciento del total de sus actos, y los referidos a temas de producción un 26,1 por ciento. En cambio, la actuación de los legisladores aquí invierte el modelo tradicional y contrasta con su patrón de participación en comisiones (ver el Cuadro 2), con un 30,8 por ciento de sus iniciativas centradas en temas reproducti-

mente la autoría originaria. Aunque esta opción deja afuera una parte importante de la actuación parlamentaria de ambas poblaciones de estudio (por ejemplo, todos los proyectos de ley firmados por más de un/a legislador/a, que son la gran mayoría de los casos), el trabajar a partir solamente de fuentes documentales (impresas y electrónicas) constituye la única manera en que se puede identificar la agencia individual de los y las legisladores y por lo tanto controlar la incidencia de la variable sexo.

17. El registro de los pedidos de informes tiende a ser muy breve en su descripción, lo que dificulta la tarea de clasificarlos por temática. 
vos y un 27,8 por ciento en temas productivos. No obstante, cabe señalar que la distribución global de temáticas en el universo de los actos parlamentarios es muy distinta a su distribución en el universo de las comisiones: en éste las productivas representan la mayoría (un 39,4 por ciento, frente a un 38,5 por ciento de comisiones reproductivas, ver Cuadro 2), mientras que en aquél, los actos productivos son una minoría (un 26,8 por ciento del total, frente a un 37,9 por ciento de reproductivos) ${ }^{18}$. Por lo tanto, la inversión de la tradicional división sexual en este caso se puede considerar como menos significativa que en el caso de la participación en comisiones de las mujeres reelectas (ver arriba).

\section{Cuadro 8}

Actos parlamentarios por sexo, según temática

\begin{tabular}{|c|c|c|c|c|}
\hline & & $\begin{array}{l}\text { Presentados } \\
\text { por mujeres }\end{array}$ & $\begin{array}{l}\text { Presentados } \\
\text { por hombres }\end{array}$ & $\begin{array}{c}\text { Total } \\
\text { presentados }\end{array}$ \\
\hline Total & & 341 & 234 & 575 \\
\hline \multirow[t]{2}{*}{ Reproducción } & Número & 146 & 72 & 218 \\
\hline & $\%$ del total & 42,8 & 30,8 & 37,9 \\
\hline \multirow[t]{2}{*}{ Producción } & Número & 89 & 65 & 154 \\
\hline & $\%$ del total & 26,1 & 27,8 & 26,8 \\
\hline \multirow[t]{2}{*}{ Sistema } & Número & 53 & 39 & 92 \\
\hline & $\%$ del total & 15,5 & 16,7 & 16,0 \\
\hline \multirow[t]{2}{*}{ Otro } & Número & 53 & 58 & 111 \\
\hline & $\%$ del total & 15,5 & 24,8 & 19,3 \\
\hline
\end{tabular}

Fuente: Elaboración propia en base a datos del sitio web y el Diario de Sesiones del Parlamento.

Finalmente, para una primera aproximación a la pregunta de si las legisladoras representan a las mujeres en su quehacer parlamentario, en la sistematización de los datos se identificaron aquellos actos con contenido de género, definido para los propósitos de este estudio como todo acto que defienda los derechos de las mujeres, que busque promover la equidad e igualdad de género, que visibilice problemáticas específicas generadas por las relaciones desiguales de género, o que rescate la contribución contemporánea o histórica de las mujeres a la vida de la na-

18. La explicación de este mayor sesgo hacia temáticas reproductivas en el universo de los actos parlamentarios tiene que ver con la menor jerarquía de los actos incluidos en el universo -las exposiciones son menos importantes en términos de su impacto en la sociedad en su conjunto o en el sistema político- y de los actos de mayor jerarquía (los proyectos de ley) sólo se incluyeron aquéllos de iniciativa exclusiva de cada legislador/a. 
ción. Paralelamente, y como manera de abordar la pregunta más amplia que se refiere a la supuesta "ética del cuidado" de las mujeres, también se identificaron aquellos actos que defienden los derechos de otros sectores sociales discriminados, marginados o vulnerables. El Cuadro 9 muestra que la gran mayoría de tales actos son realizados por mujeres.

\section{Cuadro 9}

Actos parlamentarios en defensa de sectores discriminados, por sexo

\begin{tabular}{lccc}
\hline Contenido & Número actos & $\begin{array}{c}\text { Porcentaje presentados } \\
\text { por mujeres }\end{array}$ & $\begin{array}{c}\text { Porcentaje presentados } \\
\text { por hombres }\end{array}$ \\
\hline Género & 26 & 96,2 & 3,8 \\
Sectores pobres & 18 & 83,3 & 16,7 \\
Infancia & 10 & 90,0 & 10,0 \\
Discapacitados & 7 & 71,4 & 28,6 \\
Adultos mayores & 5 & 60,0 & 40,0 \\
Afrodescendientes & 1 & 100,0 & 0,0 \\
\hline
\end{tabular}

Fuente: Elaboración propia en base a datos del sitio web y el Diario de Sesiones del Parlamento.

Los datos presentados hasta ahora muestran que el sexo es una variable significativa tanto con respecto al volumen como al enfoque temático de la actuación parlamentaria de mujeres y hombres. En términos globales, pero también en casi todos los casos cuando se desagregan los datos por temática, las legisladoras tienen una actuación más prolífica que los legisladores. Por otro lado, tanto el análisis de la participación en comisiones como de la presentación de iniciativas tiende a confirmar el patrón tradicional de la división sexual del trabajo en el quehacer parlamentario: en general las mujeres priorizan temas reproductivos, mientras que los hombres se centran mayoritariamente en temas productivos. No obstante, el hecho que el volumen de trabajo parlamentario de las legisladoras en ambos indicadores sea mayor que el de los legisladores hace que su preocupación por los temas productivos esté a la par de la de los varones, y que su mayor interés en temas reproductivos sea un agregado y no un sustituto a ésta. Además, en general, el perfil temático de la actuación de los hombres parlamentarios reproduce más fuertemente la tradicional división sexual del trabajo que el de las mujeres.

\section{¿Las mujeres representan a las mujeres?}

Los datos del Cuadro 10 muestran que las legisladoras son más propensas que sus pares varones a presentar iniciativas de género. En esta sección se indaga más en el rol que tienen las legisladoras en la promoción 
de temas de género en la agenda parlamentaria. Para esto, primero se desagregan por sexo las iniciativas de género presentadas en el período bajo estudio para ver el aporte relativo de mujeres y hombres en la elaboración de la agenda legislativa de género. Luego se adopta un enfoque cualitativo, basado en información recabada en entrevistas en profundidad con las legisladoras, para indagar más en las prácticas y estrategias de las mujeres legisladoras para la elaboración de esa agenda.

\section{Cuadro 10}

Presentación de iniciativas de género, por sexo

\begin{tabular}{|c|c|c|c|c|}
\hline & & $\begin{array}{l}\text { Exposiciones } \\
\text { verbales }\end{array}$ & $\begin{array}{l}\text { Exposiciones } \\
\text { escritas }\end{array}$ & $\begin{array}{l}\text { Proyectos } \\
\text { de ley }\end{array}$ \\
\hline Total presentados & & 28 & 17 & 22 \\
\hline $\begin{array}{l}\text { Presentados por } \\
\text { sólo mujeres }\end{array}$ & $\begin{array}{l}\text { Número } \\
\% \text { del total }\end{array}$ & $\begin{array}{c}15 \\
53,6\end{array}$ & $\begin{array}{c}6 \\
35,3\end{array}$ & $\begin{array}{c}5 \\
22,7\end{array}$ \\
\hline $\begin{array}{l}\text { Presentados por } \\
\text { sólo hombres }\end{array}$ & $\begin{array}{l}\text { Número } \\
\% \text { del total }\end{array}$ & $\begin{array}{c}11 \\
39,3\end{array}$ & $\begin{array}{c}11 \\
64,7\end{array}$ & $\begin{array}{c}4 \\
18,2\end{array}$ \\
\hline $\begin{array}{l}\text { Presentados por } \\
\text { mujeres y hombres }\end{array}$ & $\begin{array}{l}\text { Número } \\
\% \text { del total }\end{array}$ & $\begin{array}{c}2 \\
7,1\end{array}$ & $\begin{array}{c}0 \\
0,0\end{array}$ & $\begin{array}{c}13 \\
59,1\end{array}$ \\
\hline
\end{tabular}

Fuente: Elaboración propia en base a datos del sitio web y el Diario de Sesiones del Parlamento.

Para el análisis cuantitativo se tomó como universo todos los PL, EE y EV con contenido de género presentados en la XLV legislatura.

Recordando que las legisladoras constituían sólo un 11,5 por ciento del parlamento en el período bajo estudio, el Cuadro 10 muestra que ellas fueron responsables en forma exclusiva de más de la mitad de las exposiciones verbales, más de un tercio de las exposiciones escritas y casi un cuarto de los proyectos de ley con contenido de género. Sólo en el número de exposiciones escritas la actuación de los legisladores supera la de las mujeres. Éstas también participaron conjuntamente con colegas varones en la presentación de casi un 60 por ciento de los proyectos de ley.

Ahora examinemos los datos relativos a la presentación de iniciativas de género por mujeres, para ver si existen diferencias dentro del grupo de legisladoras. El Cuadro 11 muestra que en la XLV legislatura casi todas las mujeres legisladoras asumieron en mayor o menor grado un rol de defensoras de los derechos de las mujeres en su quehacer parlamentario. 


\section{Cuadro 11}

Iniciativas de género presentadas por legisladoras titulares*

\begin{tabular}{lccccccc}
\hline & \multicolumn{3}{c}{ Cámara } & & \multicolumn{3}{c}{ Partido } \\
\cline { 2 - 3 } \cline { 5 - 7 } Tasa iniciativas de género & Casos & Senado & Representantes & EP-FA & PC & PN \\
\hline Nula (0 iniciativas) & 2 & 1 & 1 & & 0 & 1 & 1 \\
Baja (1-3) & 2 & 1 & 1 & & 1 & 0 & 1 \\
Media (4-6) & 7 & 1 & 6 & & 4 & 3 & 0 \\
Alta (7-9) & 2 & 0 & 2 & & 1 & 0 & 1 \\
Muy alta (10 o más) & 2 & 0 & 2 & 2 & 0 & 0 \\
\hline
\end{tabular}

* Se contabilizaron todas las iniciativas firmadas por las legisladoras, ya sea en forma exclusiva o conjuntamente con otras/os legisladoras/es.

Fuente: Elaboración propia en base a datos del sitio web y el Diario de Sesiones del Parlamento

De un total de 15 parlamentarias, sólo una senadora y una diputada no presentaron ninguna exposición ni proyecto de ley con contenido de género. En el otro extremo, dos diputadas presentaron un número muy alto -12 y 13- de iniciativas de género. Casi la mitad de las legisladoras registran una tasa media de iniciativas de género. Con respecto a la variable "reelección", no parece tener relevancia, ya que en todos los niveles se encuentran tanto legisladoras nuevas como reelectas. En cambio, la desagregación por partido muestra que las mayores tasas de actividad se encuentran entre las mujeres del EP-FA. De hecho, si calculamos el promedio de iniciativas por legisladora y por partido, la tasa de este partido duplica la de los otros dos partidos, los cuales, por su parte, tienen tasas muy parecidas: las frentistas presentaron un promedio de 6,8 iniciativas cada una, las blancas 3,3 y las coloradas 3,7.

¿Cuál podría ser la explicación de esta diferencia? Aunque es verdad que en la época post-dictadura la izquierda uruguaya se ha manifestado algo más abierta a la promoción de los temas de género que los otros dos partidos principales ${ }^{19}$, de todas formas sigue existiendo un nivel significativo de resistencia hacia la temática en esa fuerza política. Por otro lado, las mujeres políticas de todos los partidos han desarrollado niveles similares de militancia de género tanto en espacios partidarios como

19. Por ejemplo, los pocos partidos que han adoptado sistemas de cuotificación para promover la elección de mujeres a cargos de decisión son todos de izquierda o centroizquierda; también, la Comisión de la Mujer instalada en el gobierno municipal frenteamplista en Montevideo ha logrado una institucionalidad mucho mayor que el mecanismo para el avance de las mujeres que ha funcionado a nivel nacional bajo gobiernos colorados y nacionalistas (ver Johnson, 2003a y 2003b). 
interpartidarios ${ }^{20}$. Más allá del sesgo que resulta de comparar grupos numéricamente tan pequeños y disímiles ( 8 frenteamplistas, frente a 4 coloradas y sólo 3 blancas), la explicación más factible es que estas diferencias en realidad se deben a la incidencia de otra variable -la de militancia de género-, que en el pequeño universo tratado tiene una alta correlación con la variable partido.

Las cuatro legisladoras que alcanzan tasas altas o muy altas en la presentación de iniciativas de género -tres de las cuales son del EP-FA- tenían todas trayectorias de militancia en temas de género. Ésta se desarrollaba ya sea en los espacios de mujeres al interior de sus partidos, en coordinadoras interpartidarias de mujeres políticas, en conjunto con organizaciones sociales de mujeres, o -en el caso de las dos que fueron reelectaspresentando o defendiendo iniciativas de género durante su carrera parlamentaria y entrando también en contacto con diversas organizaciones de mujeres que realizan actividades de cabildeo parlamentario en torno a temas de género. En suma, es esta presencia de mujeres con "conciencia de género" que parece ser en el caso uruguayo la clave para la generación de las condiciones necesarias para transformar la aún escueta presencia femenina parlamentaria en una masa crítica.

\section{La Bancada Femenina}

El 8 de marzo de 2000 se creó la Bancada Femenina, a iniciativa especialmente de tres nuevas diputadas (una de cada partido), quienes ya venían actuando en otras instancias de coordinación interpartidaria. Ellas habían sido en su momento coordinadoras por sus respectivos partidos de la Red de Mujeres Políticas, una coordinación nacional creada en 1992 entre mujeres militantes, y en cargos legislativos y ejecutivos -nacionales y departamentales- de los cuatro lemas con representación parlamentaria. La Red tenía como objetivo inicial:

[...] el intercambio de ideas, iniciativas y toma de posiciones de las mujeres representantes de los distintos partidos políticos, a los efectos de analizar, estudiar y proponer políticas y legislaciones que defiendan los derechos de la mujer, coordinando acciones a nivel nacional e internacional, en los temas que la comprendan ${ }^{21}$.

Durante ocho años la Red se dedicó a formar a mujeres políticas para “ejercer la cuota de poder que tienen"22. Para las fundadoras de la Red,

20. En Uruguay existe una larga tradición de articulación interpartidaria entre mujeres políticas, empezando con la Concertación de Mujeres que se creó a la salida de la dictadura en 1984 para tratar de asegurar la inclusión de temas comunes de género en la nueva agenda política democrática, hasta la Bancada Femenina creada en 2000 (ver más adelante). 21. Documento de la Red de Mujeres Políticas, "Estatutos de Creación de la Red de Mujeres Políticas del Uruguay", 22 de julio de 1992.

22. Entrevista con una de las coordinadoras de la Red. 
no era una cuestión simplemente de mejorar las oportunidades para las mujeres en política, sino de producir líderes mujeres con una conciencia y una agenda de género, y la voluntad de perseguir esa agenda dentro de sus respectivos partidos: "[...] las queremos hacer feministas. Y que estén dispuestas a pelear dentro de sus partidos" 23 . Esta práctica acumulada de promover un enfoque de género en ámbitos de la política institucional y la experiencia de largo aliento de buscar entre mujeres de distintos partidos la unidad en la diversidad facilitó la consolidación de una identidad colectiva de género en el ámbito parlamentario.

La Bancada Femenina se conformó como una coordinación horizontal ${ }^{24}$, transversal, e interpartidaria, abierta a toda legisladora titular o suplente que quisiera integrarla. En el curso del período todas las parlamentarias titulares y varias suplentes participaron en diversas actividades de la Bancada -entrevistas con representantes de distintos organismos del Poder Ejecutivo y de organismos internacionales, seminarios y conferencias organizados conjuntamente con instituciones académicas u organizaciones sociales de mujeres, conferencias de prensa, homenajes, además de la presentación y promoción de iniciativas legislativas. La conformación de la Bancada Femenina resultó ser una estrategia efectiva para lograr avances legislativos en materia de género y para señalar que eran temas que atañían a todas, más allá de sus diferencias ideológico-partidarias. Una diputada lo describió como "una visualización pública de cómo creemos las mujeres que tiene que trabajarse desde el punto de vista político: avanzar en lo que nos une y trabajar en lo que nos separa" 25 .

Los primeros actos colectivos de la Bancada Femenina fueron la solicitud de creación de una Comisión Especial de Género y Equidad (CEGE) en la Cámara de Representantes, la petición de desarchivo de dos proyectos de $l e{ }^{26}$ que habían sido presentados en la anterior legislatura y habían sido archivados por reglamento cuando ésta se terminó, y la presentación de tres nuevos proyectos de ley ${ }^{27}$. Estos tres actos de alguna manera ejemplifican las estrategias adoptadas por las mujeres parlamentarias para incidir en la agenda legislativa durante el resto del período.

23. Ibid.

24. "[...] una de las características de la bancada femenina es que no tiene coordinadora ni Presidenta, todas somos lo que somos, mujeres legisladoras, todas iguales, trabajando juntas", diputada Glenda Rondán (PC) en el "Encuentro sobre coordinación de políticas sociales" organizado por la Bancada Femenina con ministros y representantes de otros organismos del Poder Ejecutivo (30 de abril de 2003).

25. Diputada Beatriz Argimón (PN), en la Rendición de Cuentas de la Bancada Femenina, Período Legislativo 2000-2005.

26. PL CRR $3538 / 1999$ (CSS 615/2001) sobre violencia doméstica y PL CRR 261/1990 sobre licencia por adopción.

27. PL CRR 63/2000 (CSS 118/2000) sobre licencia para trabajadoras de los sectores público y privado para realizarse los exámenes de cáncer génito-mamario; PL CRR 62/2000 sobre igualdad de derechos de los cónyuges en las sociedades cooperativas; y PL CRR 64/ 2000 sobre licencia para padres y madres en caso de la enfermedad de sus hijos/as. 
La primera de estas estrategias fue la presentación de proyectos de ley firmados por legisladoras de más de un partido. Con ello se pretendía, más que procurar la identificación de ciertos temas como "de mujeres", demostrar la existencia de un determinado nivel de consenso interpartidario, lo que facilitaría el tratamiento y aprobación de tales iniciativas. De hecho, las parlamentarias se preocuparon que sus correligionarios varones también firmaran los proyectos presentados, con la expresa intención de que no fuesen vistos como "cosas de mujeres". El alto porcentaje de proyectos presentados conjuntamente por mujeres y hombres (ver el Cuadro 10) da cuenta de la efectividad de esta estrategia y refleja además una apertura de parte de los legisladores firmantes para considerar los temas de género como demandas legítimas que requieren acciones legislativas.

La segunda estrategia surgió del reconocimiento de que la Bancada Femenina, a pesar de que desarrollaba prácticas innovadoras y de mucho impacto en el ámbito parlamentario, estaba inserta en una realidad institucional cuyas normas y prácticas formales podrían coartar su margen de influencia. Ya que la Bancada Femenina era -y siempre sería- una "instancia de trabajo no institucionalizada"28, la creación de la CEGE era necesaria en tanto permitía el acceso formal a los procesos legislativos y a los canales de interacción y control existentes tanto al interior del Parlamento como entre el Poder Legislativo y el resto de los organismos del Estado.

Lograr la creación de la CEGE no fue difícil; desde 1988 había existido en la Cámara de Representantes una Comisión Especial sobre la Condición de la Mujer. El desafío residía en superar los problemas de funcionamiento que había tenido en períodos anteriores y transformarla en un órgano efectivo desde el cual promover una agenda legislativa de género. En el curso de la LXV legislatura, se citó a 88 reuniones de la CEGE, de las que 87 obtuvieron quórum; en el período anterior la Comisión Especial sobre la Condición de la Mujer y Familia había citado a sus integrantes a un total de 36 reuniones, para las cuales sólo hubo quórum 31 veces.

Sin duda, el factor determinante de esta mejora en el rendimiento de la Comisión fue el compromiso real que tenía la gran mayoría de sus integrantes con la temática, y la presencia entre sus filas de las mismas tres diputadas que anteriormente habían sido coordinadoras de la Red de Mujeres Políticas. Su experiencia acumulada de trabajar juntas en su militancia de género también hizo que existiera la confianza mutua como para priorizar la obtención de resultados concretos por encima de cuestiones formales. Así, la división de tareas -por ejemplo, el relaciona-

28. Diputada Beatriz Argimón (PN) en el "Encuentro sobre coordinación de políticas sociales". 
miento con los medios, con organizaciones sociales de mujeres, solicitudes de entrevistas con miembros del Poder Ejecutivo, etc.- se hacía en base a los puntos fuertes de cada una, más allá de quiénes ocupaban los cargos formales de responsabilidad de la Comisión.

La tercera estrategia fue el ágil manejo de las normas que rigen el proceso legislativo, para aligerar el tratamiento de los proyectos presentados. Por ejemplo, la definición de cuál es la comisión que debe estudiar un proyecto ingresado al Parlamento constituye una decisión que incumbe, en primera instancia, al presidente del cuerpo legislativo, quien asigna los nuevos proyectos a la comisión a la cual le parece que corresponde la temática. Esta decisión puede tener relevancia en las siguientes cuestiones: primero, en cuanto a la prioridad que se le asigna al proyecto, que no sólo tiene que ver con su valor intrínseco, sino con la cantidad y naturaleza de los asuntos que la comisión ya tiene en estudio y los intereses personales y partidarios de los y las miembros de la comisión; segundo, en la calidad y enfoque del tratamiento que recibe, que depende en gran parte del perfil de los y las integrantes; y tercero, en el destino final del proyecto; si se eleva sin modificar a la Cámara para su discusión, o si se redacta un proyecto sustitutivo, o si simplemente se archiva.

En el caso de dos proyectos de ley, integrantes de la Bancada Femenina solicitaron la rectificación del trámite para que fueran enviados a otra comisión. El primer caso fue el de los cuatro proyectos de ley sobre aborto presentados en legislaturas anteriores, cuyo desarchivo fue solicitado por la CEGE. Cuando el presidente de la Cámara le asignó a la propia CEGE la responsabilidad por el estudio de los proyectos, se pidió que se rectificara el trámite y que se los mandara a la Comisión de Salud Pública y Asistencia Social (CSPAS). Los miembros plenos de la CSPAS eran todos hombres y médicos, la mayoría de los cuales -las parlamentarias sabían-, apoyaban la despenalización del aborto. Que fuera la CSPAS y no la CEGE la que redactara el nuevo proyecto de ley, era una cuestión estratégica por dos razones. Primero, al provenir de una comisión que concentraba miembros de la comunidad científica, el proyecto tendría mayor peso y legitimidad a los ojos del resto del Parlamento y de la opinión pública, que si hubiese sido aprobado por una comisión integrada casi en su totalidad por mujeres ${ }^{29}$, de las cuales varias se autoidentificaban como feministas. La otra razón es que la despenalización del aborto constituía un tema que dividía a las mujeres miembros de la CEGE. Por lo tanto, el que la CSPAS se encargara de redactar el nuevo proyecto de salud reproductiva permitía evitar la polarización de posiciones en el seno del órgano que de alguna manera simbolizaba la unidad de las mujeres políticas. A pesar de que ninguna diputada integraba

29. Entre los siete miembros plenos de la CEGE había un hombre, el diputado Pablo Mieres del Nuevo Espacio, lema sin representación femenina titular. 
la CSPAS, algunas asistieron como delegadas en varias ocasiones durante el proceso de estudio del proyecto para asegurarse de que el asunto siguiera buen camino ${ }^{30}$.

En contraste, en el caso de otro proyecto ${ }^{31}$ que también estaba relacionado con la salud reproductiva pero que inicialmente fue enviado a la CSPAS, las diputadas solicitaron que se rectificara el trámite para que este proyecto sí se enviara a la CEGE. ¿Por qué se actuó en este caso totalmente al revés? Este proyecto, que ya había sido sancionado en el Senado, establecía el derecho de la parturienta a estar acompañada por una persona de su elección en todo momento del parto. En Uruguay, la tendencia en el sistema de salud sigue siendo de tratar a la parturienta como una paciente que se somete a una intervención médica, priorizando la comodidad y las necesidades del ginecólogo por encima de las de la mujer. Por lo tanto, enviar a una comisión compuesta totalmente por médicos un proyecto que contradecía este marco de valores, hubiera equivalido a enterrar la iniciativa. En cambio, permitió que la CEGE pudiera asegurarse de que esta propuesta que jerarquizaba los derechos y el protagonismo de la mujer parturienta se sancionara como Ley 17.386.

El impacto de la Bancada Femenina en la vida parlamentaria tuvo varias dimensiones. Por un lado, representaba una modalidad de trabajo interpartidario poco común en un ámbito legislativo en general fuertemente marcado por las divisiones partidarias. Aunque durante la misma legislatura se dieron instancias de coordinación a nivel de bancadas departamentales (Canelones y la litoral), ésas eran estrategias contingentes construidas en reacción a acontecimientos coyunturales (por ejemplo, las inundaciones en Canelones). En cambio, la Bancada Femenina representaba una estrategia proactiva de largo plazo, que supo superar desafíos puntuales potencialmente divisorios, como la presentación o discusión de proyectos sobre temas -como la cuota o el aborto- que no gozaban del apoyo de todas sus integrantes. En el éxito de esta estrategia fue fundamental la concepción de la "unidad" de la Bancada, no en términos de unanimidad de consenso sobre todos los temas de género, sino en términos de respetar las diferencias y límites de cada una de sus integrantes dentro de un marco compartido de convicción en cuanto a que había que abrir un espacio para estos temas en la agenda legislativa.

Por otro lado, todas las mujeres parlamentarias hacían una evaluación positiva no sólo de lo que se había logrado en materia legislativa, sino del impacto que había tenido sobre la participación política de la mujer en el Parlamento en términos más generales. Este impacto a su vez tenía una triple resonancia. Primero, al interior del conjunto de mujeres parla-

30. El proyecto (PL CRR 3107/1993; CSS 984/2002) salió de la CSPAS con informes en mayoría y minoría. Después de una larga discusión en la Cámara baja, fue sancionado, pero por tres votos no logró aprobarse en el Senado.

31. PL CSS 290/2000 (CRR 1254/2001). 
mentarias; segundo, para cada una de ellas. La "solidaridad de género" de la cual la existencia de la Bancada Femenina dependía, pero que también contribuía a fortalecer, hacía que las mujeres se sintieran respaldadas en su actuación parlamentaria:

Las mujeres ya sabemos, cuando, por ejemplo, vamos a hablar en el plenario, que hay otras que nos van a escuchar, que nos apoyan y nos acompañan en nuestra acción, aunque no necesariamente en nuestra intención legislativa ${ }^{32}$.

[...] en lo personal me permitió avanzar en los temas sabiendo que no estaba sola, lisa y llanamente porque aun en temas en los que ni siquiera íbamos a tener pronunciamientos iguales, manejamos códigos de relacionamiento basados en el entendimiento y en el más absoluto respeto ${ }^{33}$.

También sabían que existía un grupo de mujeres que las apoyaría frente a cualquier experiencia discriminatoria, algo que seguía existiendo (por ejemplo, comentarios o bromas sexistas) aunque -constataron las reelectas- con mucho menos frecuencia.

El segundo efecto de la presencia de la Bancada Femenina, entonces, es justamente el cambio de actitud de los varones hacia las mujeres y su accionar legislativo. El récord exitoso de la Bancada Femenina en lograr la concreción de iniciativas legislativas y su perduración a pesar de las diferencias entre sus integrantes, y a pesar de los pronósticos de ruptura de parte de los hombres, demostraban que "las mujeres se juntan y hacen cosas, logran cosas" 34 .

Tercero, esta impresión de la efectividad de la actuación parlamentaria de las mujeres también quedó presente en el imaginario público. La existencia de la Bancada Femenina hizo más visibles a las legisladoras para la opinión pública, a través de una prensa que supo aprovechar su valor de novedad. La resonancia de la Bancada Femenina en la opinión pública se puede ilustrar con referencia al hecho que muchas veces las mujeres que traen denuncias o reivindicaciones al Parlamento piden hablar no con los o las representantes de su departamento, ni siquiera con la CEGE, sino justamente con la Bancada Femenina. Es decir, por lo menos entre esta población existe la idea de que las parlamentarias representan a las mujeres.

\section{Conclusiones}

Este artículo ha pretendido ser un aporte a los debates en torno a si existen diferencias en cómo mujeres y hombres hacen política y si las

32. Entrevista con una integrante de la Bancada Femenina.

33. Diputada Argimón, en la Rendición de Cuentas de la Bancada Femenina, Período Legislativo 2000-2005.

34. Entrevista con una integrante de la Bancada Femenina. 
mujeres representan a las mujeres. Cabe reiterar aquí que el número reducido de casos hace que sea imposible proyectar conclusiones generalizables en base a los resultados de este estudio. Lo que se puede afirmar es que en el caso de las legisladoras de la XLV legislatura el sexo sí hace la diferencia.

Respecto al análisis cuantitativo, se ha visto, por un lado, que las parlamentarias eran más prolíficas en su actuación legislativa que los legisladores de la muestra, un dato no sin relevancia en una época en la cual el Parlamento -como el resto de las instituciones políticas- está desacreditado a ojos de la opinión pública. El estudio también ha mostrado que existían diferencias entre la actuación parlamentaria de las legisladoras y los legisladores en cuanto a su enfoque temático. Aunque ambos grupos reproducían la tradicional división sexual del trabajo en su actuación parlamentaria, en el caso de las parlamentarias este sesgo generalmente era menos marcado y en algún caso se invertía significativamente. Además, el mayor volumen global de la actuación femenina hacía que su dedicación a la temática tradicionalmente vista como masculina -producción- estuviera de todas formas en la mayoría de los casos a la par de la de sus colegas varones. Es decir, las legisladoras no descuidaban los temas productivos aun cuando mostraban una particular preocupación por temas reproductivos. Esto último quedó también reflejado en el hecho de que fueran responsables de la gran mayoría de iniciativas que defendían los derechos de sectores sociales discriminados o vulnerables.

Por otro lado, los datos sobre la actuación individual de las legisladoras indican que la mayoría de éstas se sentían representantes de las mujeres, lo que las condujo a tomar iniciativas para defender los derechos o representar los intereses de las mismas como parte de su labor parlamentaria. Las diferencias al interior del universo de las parlamentarias estaban dadas más por lo que podemos llamar conciencia de género que por cualquier otra variable. La presencia de mujeres con largas trayectorias de militancia de género también es la clave para entender cómo se logró transformar una pequeña minoría de legisladoras en una masa crítica capaz de estrategias de acción colectiva en la promoción y defensa de los derechos de las mujeres. La conformación de la Bancada Femenina y el manejo hábil del proceso legislativo permitieron que se promoviera una agenda legislativa de género colectiva, a pesar de las diferencias entre las legisladoras, tanto político-partidarias como respecto a las posiciones adoptadas frente a los temas más polémicos de la agenda de género.

Finalmente, cabe señalar que el hecho de que la clave de la consolidación de la masa crítica en esa legislatura se encontrara en la presencia de determinados individuos, plantea la posibilidad de que la continuidad de esa masa crítica dependa de la presencia continuada de esas mujeres, o de la entrada de otras con perfiles parecidos. Algo que no es tan fácil de garantizar en un sistema político-partidario que no ha seguido la 
tendencia regional de adoptar mecanismos concretos para asegurar el ingreso de más mujeres a cargos electivos.

\section{Bibliografía}

Dahlerup, Drude. 1993. “De una pequeña a una gran minoría: una teoría de la masa crítica en la política escandinava". Debate Feminista 4 (8): 165-206.

De Barbieri, Teresita. 2003. Género en el Trabajo Parlamentario. La Legislatura Mexicana a Fines del Siglo XX. Buenos Aires: CLACSO.

Dodson, Debra L. y Susan J. Carroll. 1991. Reshaping the Agenda: Women in State Legislatures. New Brunswick: Center for the American Woman and Politics.

Fernández Poncela, Anna M. 2004. “Leyes, elecciones, cámaras y mujeres". La Ventana 4 (19): 72-130.

Gilligan, Carol. 1982. In a different voice: Psychological theory and women's development. Cambridge, MA: Harvard University Press.

Htun, Mala y Mark Jones. 2002. “Engendering the right to participate in decision-making: electoral quotas and women's leadership in Latin America". En Maxine Molyneux y Nikki Craske (eds.), Gender and the politics of rights and democracy in Latin America. Londres: Palgrave, 32-56.

Johnson, Niki. 2000. “¿Democracia a medias? La representación de la mujer en cargos políticos electivos en el Uruguay, 1984-1994". Revista Uruguaya de Ciencia Política 12: 69-96.

2003a. "Mecanismos estatales para el avance de las mujeres en el Uruguay". En Cotidiano Mujer, La equidad de género en el Estado. ¿A quién le importa? Montevideo: Cotidiano Mujer, 43-54.

2003b. "La cuota: ¿un mecanismos necesario y efectivo para incrementar la participación de mujeres en cargos políticos electivos? El caso uruguayo". Ponencia presentada en el Seminario Estrategias políticas de género: reformas institucionales, identidad y acción colectiva. Instituto de Investigaciones Gino Germani, Facultad de Ciencias Sociales, Universidad de Buenos Aires. Agosto.

Jones, Kathleen. 1993. Compassionate authority: Democracy and the representation of women. Londres: Routledge.

Peschard, Jacqueline. 2004. “El sistema de cuotas en América latina: Panorama general". En IDEA, La aplicación de las cuotas: Experiencias latinoamericanas. Informe del taller, Lima, febrero de 2003. Estocolmo: International Institute for Democracy and Electoral Assistance, 22-31.

Sinkkonen, Sirkka y Elina Haavio-Mannila. 1981. “The impact of the women's movement and legislative activity of women MPs on social development". En Margherita Rendel (ed.). Women, Power and Political Systems. Nueva York: St Martin's Press, 195-215.

Skard, Torild, Elina Haavio-Mannila et al. 1985. "Women in parliament". En Elina Haavio-Mannila et al. Unfinished Democracy: Women in Nordic Politics. Oxford: Pergamon Press, 51-80. 
Swers, Michele L. 1998. "Are women more likely to vote for women's issue bills than their male colleagues?". Legislative Studies Quarterly 23 (3): 435-448.

Thomas, Sue. 1994. How Women Legislate. Oxford: OUP.

Tremblay, Manon. 1998. “Do female MPs substantively represent women? A study of legislative behaviour in Canada's 35th Parliament". Canadian Journal of Political Science 31 (3): 435-465.

Tremblay, Manon y Réjean Pelletier. 2000. “More feminists or more women? Descriptive and substantive representation of women in the 1997 Canadian federal elections". International Political Science Review 21 (4): 381-405.

Trimble, Linda. 1997. "Feminist politics in the Alberta legislature, 1972-1994". En Jane Arscott y Linda Trimble (eds.), In the Presence of Women: Representation in Canadian Governments. Toronto: Harcourt Brace \& Company, 128-153.

1998. "Who's represented? Gender and diversity in the Alberta legislature". En Manon Tremblay y Caroline Andrew (eds.), Women and Political Representation in Canada. Ottawa: University of Ottawa Press, 259-289. 